during fatigue, prepared by him and Dr. N. J. Wadsworth, described the work carried out at the H. H. Wills Physical Laboratory in which simultaneous observations were made of the metallographic changes visible on the surface, and of the changes in energy dissipation which take place during the fatiguing of copper, nickel and cadmium. From the results of this work Dr. Thompson showed that there is no direct connexion between the changes in energy dissipation and the progress towards fatigue failure.

The development of non-destructive inspection methods for non-metallic materials presents a difficult but, nevertheless, intensely interesting field of investigation for physicists. As in the case of metals, the promise of improved techniques is most likely to be found from studies made of the effects of structure on physical properties. Dr. P. T. Barrett (Terylene Council, Imperial Chemical Industries, Ltd.) reviewed the work which has been carried out on the development of tests for plastic fibres. In his paper on the testing of fibres and their molecular structure, he described the methods of physical measurement which provide information about the structure of fibres, and he discussed the mechanical properties of fibres in terms of their molecular structure.

It is one of the aims of the Non-Destructive Testing Group to encourage discussion on research investigations which have not necessarily been embarked upon for the purposes of non-destructive testing, but which are likely to produce results of use in the development of new non-destructive testing methods. In this connexion, four papers were presented at the meeting. Three of these described work in progress at the Atomic Energy Research Establishment, Harwell, and the fourth work which has been carried out at the National Physical Laboratory, Teddington.

Dr. L. E. Drain's paper on the principles and applications of nuclear magnetic resonance made an impressive contribution to the rims of the meeting. $\mathrm{He}$ enumerated twelve applications to which the measurements involved in his work could be put, and six of these applications were of direct use for the purposes of non-destructive testing. $\mathrm{Mr}$. W. A. Runciman read a paper on optical fluorescence in non-destructive testing, in which he described the phenomenon of optical fluorescence and showed that, in addition to its use for detecting surface defects, it can be applied to problems of chemical and microscopic examination of materials. Mr. S. F. Pugh, in his paper on the effects of penetrating radiations on materials, reviewed present knowledge on radiation damage and indicated how the results of work in progress on this subject are likely to provide in formation on the structure of materials. Finally, Mr. M. F. Markham (National Physical Laboratory) gave a paper on the measurement of elastic constants by the ultrasonic pulse method. In this Mr. Markham described the propagation of stress pulses in æolotropic media, and the information he provided is not only of value from the point of view of establishing new techniques for the measurement of elastic constants, but also its application to the technology of ultrasonic inspection is of considerable importance.

The attendance at this meeting was one of the largest which the Non-Destructive Testing Group has had at its summer meetings, and it is the hope of the Group that the enthusiasm shown throughout the whole programme by those present is indicative of the fact that in the future there will be ample support given to the Group in its task of disseminating information on the physics of non-destructive testing. E. G. STANFORD

\section{PLANT BREEDERS' CONFERENCE AT CAMBRIDGE}

$\mathrm{W}$ HEN the first conference of plant breeders was called by the Agricultural Research Council in 1947, forty workers met at the Plant Breeding Institute, Cambridge, then a research institute of the School of Agriculture, to discuss their common problems and to learn something of the work in progress there. In the intervening years the conference met annually until 1950 and biennially since then, inspecting work and discussing mutual problems; the meetings have been held at the John Innes Horticultural Institution, first at Merton and later at Bayfordbury, at the Welsh and Scottish Plant Breeding Stations, and at the station at Loughgall of the Plant Breeding Division of the Ministry of Agriculture, Northern Ireland. With the seventh meeting held on July 4 and 5 at the Plant Breeding Institute, Cambridge, the initial cycle has been completed. The expansion of effort in plant breeding is indicated by the increase in the number of participants to 105 at this meeting, and by the fact that since the first meeting the four main plant breeding centres in Great Britain have been transferred to new stations to provide facilities adequate for the expansion that has occurred.

During the morning sessions, members of the staff of the Plant Breeding Institute gave short talks, which were followed by informal discussions. The afternoons were divided between tours of the fieldplots and glasshouses, designed mainly to provide an indication of the scope of the work, and laboratory demonstrations and informal discussions between specialists to allow them to fill in the details of particular interest.

R. Riley gave an outline of the work on alien chromosome addition with reference to wheat breed. ing. Here the object has been to introduce new genes for particular desirable characters from primitive related species into wheat. From the results so far obtained in the production of new synthetic amphidiploids, the introduction of complete genotypes appears to bring in too many undesirable characters with the good. The work discussed concerns the addition to hexaploid wheat of single pairs of chromosomes from rye; new plants with the addition to wheat of six of the seven rye chromosomes, both as disomics and as monosomics, were shown, as well as some in which only a pari of a rye chromosome had been added. Initially the new forms tend to revert to the euploid condition, but it seems likely that balance may eventually be achieved.

K. F. Thompson discussed sporophytic incompatibility with special reference to the possibility of using a set of clones to produce commercial quantities of double-cross seed of uniform types of marrow stem kale. The interpretation of the data so far accumulated is complicated by the range of partial compatibility shown in some crosses, and by the firding that in other members of the family the degree of compatibility varies, probably with environmental differences. 
In a survey of the outlook for herbage breeding, J. L. Fyfe stressed the advantages to the breeder of having clearly defined objectives to aim at in his work; a survey of the distribution and relative importance of the diseases of forage crops would facilitate the planning of the programme. He went on to discuss the general possibilities of new breeding methods based on the system used in the production of hybrid corn as compared with the older methods based on crossing and pedigree selection. Some degree of inbreeding can be of considerable value in any programme of breeding with crops which are normally cross-pollinated, evon where the aim is not the exploitation of heterosis but only the production of a good variety. Inbreeding tends to provide new and otherwise inaccessible information about the material being studied; at the same time it may so reduce the genetic variability within the breeding lines that plot-size in trials can be reduced, with $a$ consequent reduction in the cost of the trials. Once obtained, the inbred lines are available for use in strain building in the older systems, or after the newer techniques of the polycross or diallel crosses. In the discussion that followed, Dr. William Davies, director of the Grassland Research Institute, emphasized that the most important aspect of forage yield was not the absolute amount, but its distribution throughout the year-factors such as the influence of one cut upon the next and subsequent harvests must be taken into account. Other speakers mentioned difficulties in seed production; the cost may be materially affected by a character, such as stiffness of straw, having little relevance to the vegetative production of a crop.

Miss J. M. Drayner gave an account of observations on the breeding system and heterosis in field beans. Both selfing and crossing occur in the crop, and a balance is maintained because the hybrids tend to be self-pollinated and the inbreds tend to cross. Marked heterosis can be seen in hybrids between third. generation inbreds. It may be possible to produce high-yielding stocks by utilizing the tendency of inbreds to cross, coupled with the use of male sterility, recently discovered in the breeding material.

G. E. Russell discussed virus strain relationships in connexion with the virus yellows problem in sugar beet. Because there has so far been no indication that any form of immunity or resistance to this disease may exist, the work is at present concentrated on the search for tolerance to the disease. To cover a wide field as rapidly as possible, a severe necrotic strain of the virus is being used for the routine inoculations, because it normally produces distinct and severe symptoms in a few days. Although this strain is a convenient one for use in the screening tests, the proper orientation of the breeding programmo must depend on a better knowledge of the distribution and importance of the strains in the field. Dr. A. R. Trim spoke of his work on the nucleic acids of sugar beet, both in relation to genetic problems and in connexion with the problems of virus yellows. The indications are that the virus may be a ribonucleoprotein, but analysis of nucleic acids recovered from beet has not progressed far enough to provide definite evidence for this.

Selection for yield in breeding cereals was discussed by F. G. H. Lupton, who paid particular attention to modifications in the method of pedigree selection and to the improvement of techniques in yield trials. Wheat hybrids from a wide range of parent varieties are now being handled at the Plant
Breeding Institute, and to speed up the work selection in the $F_{2}$ and $F_{3}$ generations is made by eye; but from the $F_{4}$ generation onward bulks of families are included in yield trials, with only a small proportion of sub-cultures retained for multiplication. Some of the newer trial lay-outs have given improved precision, but the analysis of others is so tedious that alternative methods of comparison are being tried. Other detailed discussion included questions of plotsize and shape, and the effects of guard rows and their omission.

The problem of choice of parental combinations was mentioned by Lupton and taken a stage further by R. N. H. Whitehouse, who described a first attempt at the analysis of diallel crosses in order to assess the comparative value of four wheat varieties, differing in various characters, as parents for the production of new hybrids. He suggested that plant breeders may find the method of value in dealing with other crops.

H. W. Howard gave an account of his investigation of a potato chimera, similar to the variety Red King, that arose in a stock of the variety King Edward. In breeding behaviour the new potato resembles King Edward, indicating that only the outer layer of the apical meristem is involved in the change. In using Asseyeva's technique of eye removal to stimulate the production of adventitious buds in the lower tissues, some plants with white-skinned tubers were produced, as well as plants with tubers of the King Edward type, white splashed with pink. The mechanism of the 'mutation' for the origin of the white type remains in doubt, particularly because such types are also produced when tubers from a seedling with a splashed tuber are subjected to the Asseyeva technique.

Work demonstrated in the field and laboratory included the breeding of new winter and spring wheats with good field-characters; selection techniques have been improved by the introduction of controlled tests of resistance to rust and eye spot, and by the use of special equipment for small-scale milling and dough testing. In the improvement of barleys, yield, strength of straw, and resistance to mildew are among the desired characters in the field; to aid selection in the laboratory, routine nitrogen determinations are made and a micro-malting test has been introduced. Improvement of hardiness of winter types and resistance to frit fly in spring types are among the main points in the work on oats, where quality is being assessed by laboratory determinations of oil content and husk percentage. In the work on the cytogenetics of the Triticinae, the addition of rye chromosomes to wheat was demonstrated, and a number of synthetic amphidiploids were also shown.

An outline was given of the work on beans and clover, where the main emphasis has been on yield and resistance to pests and diseases. In lucerne the main problems concern breeding techniques and seed production ; but here, as with timothy and cocksfoot, there is the important question of achieving a balance in seasonal production in the drier parts of Britain. In marrow stem kale, uniform inbred lines differing in habit were shown; hardiness and quality are being studied in this crop. Work on potatoes has recently been extended to include resistance to eelworm in addition to the work on blight and the study of cooking quality. In sugar beet selection for resistance to bolting and the search for tolerance to virus yellows were shown. 